\title{
Arbuscular Mycorrhizal Fungi Enhance Sea Buckthorn Growth in Coal Mining Subsidence Areas in Northwest China
}

\author{
Yanxu Zhang ${ }^{1,2}$, Yinli Bi ${ }^{1,2 *}$, Huihui Shen ${ }^{1,2}$, and Longjie Zhang ${ }^{1,2}$ \\ 'State Key Laboratory of Coal Resources and Safe Mining, China University of Mining and Technology (Beijing), \\ Beijing 100083, P.R. China \\ ${ }^{2}$ College of Geoscience and Surveying Engineering, China University of Mining and Technology (Beijing), Beijing \\ 100083, P.R. China
}

\begin{abstract}
Land subsidence induced by underground coal mining leads to severe ecological and environmental problems. Arbuscular mycorrhizal fungi (AMF) have the potential to improve plant growth and soil properties. We aimed to assess the effects of AMF on the growth and soil properties of sea buckthorn under field conditions at different reclamation times. Inoculation with AMF significantly promoted the survival rate of sea buckthorn over a 50-month period, while also increasing plant height after 14, 26, and 50 months. Crown width after 14 months and ground diameter after 50 months of inoculation treatment were significantly higher than in the uninoculated treatment. AMF inoculation significantly improved plant mycorrhizal colonization rate and promoted an increase in mycelial density in the rhizosphere soil. The $\mathrm{pH}$ and electrical conductivity of rhizosphere soil also increased after inoculation. Moreover, after $\mathbf{2 6}$ and $\mathbf{5 0}$ months the soil organic matter in the inoculation treatment was significantly higher than in the control. The number of inoculated soil rhizosphere microorganisms, as well as acid phosphatase activity, also increased. AMF inoculation may play an active role in promoting plant growth and improving soil quality in the long term and is conducive to the rapid ecological restoration of damaged mining areas.
\end{abstract}

Keywords: Arbuscular mycorrhizal fungi, growth, mining subsidence, rhizosphere environment, sea buckthorn

Received: July 4, 2019 Accepted: March 9, 2020

First published online: March 13, 2020

*Corresponding author Phone: +86-10-62339048 Fax: +86-10-62339048 E-mail: ylbi88@126.com

pISSN 1017-7825 eISSN 1738-8872

Copyright(C) 2020 by The Korean Society for Microbiology and Biotechnology

\section{Introduction}

Coal is the most important energy source in China, accounting for about $70 \%$ of the national primary energy consumption [1]. With the exhaustion of coal resources in east China, the proportion of coal resource exploitation in the west has gradually increased. In recent years more than $60 \%$ of coal output has been produced in Shanxi, Shaanxi, Inner Mongolia, and Ningxia provinces in west China [2]. However, most of the western region is arid or semi-arid and the ecosystem is very fragile. Mostly underground coal mining causes deformation and movement of strata and of the ground surface leading to a series of ecological problems including land subsidence, water resource disruption, mining waste disposal and air pollution [1,3]. The mining subsidence induced by underground coal mining destroys soil structure, changes soil properties, and causes many environmental problems such as loss of soil moisture and nutrients, limitation of vegetation growth, death of plants and loss of soil microbial diversity and functioning [4-6]. Due to poor site conditions and deterioration of the environment, the function of the rhizosphere soil microbial community in the subsidence areas has declined, making plant establishment more difficult in these areas [7]. Beneficial microorganisms have been suggested as an effective and necessary tool for vegetation restoration in degraded mining areas [8].

Arbuscular mycorrhizal fungi (AMF) are common endophytic fungi that can form potentially symbiotic associations with more than $80 \%$ of terrestrial plants [9]. Mycorrhizal fungi live inside the cortex of plant roots, on the surface of the roots, or around the epidermal cells of the roots and the mycorrhizal symbiosis can affect plant growth and fitness [10]. It has been reported that AMF have the potential to increase the tolerance of their host plants to various stresses (e.g., extreme temperatures, drought, salinity, and potentially toxic metals) [11-13]. AMF mycelium can increase the uptake of nutrients by plants and promote plant growth and the yield and quality of fruit $[14,15]$. Moreover, AMF can restore or maintain soil fertility and reduce soil erosion [16, 17]. Based on these effects, AMF offer much benefit in the process of ecological restoration of reclaimed mining areas [18]. At present, many studies have applied AMF in mine reclamation and have achieved good effects [19-21]. However, most studies have been conducted under greenhouse conditions with sterilized soil and there are few reports on the effects of AMF on plant growth and the rhizosphere environment over a relatively long reclamation period under 
field conditions. Also, it is not clear whether the inoculation will work over a longer period of time. Hence, in our study we aimed to evaluate the role of arbuscular mycorrhizal inoculation on plant growth and soil properties over different reclamation periods of up to 50 months in coal mining subsidence areas.

\section{Materials and Methods}

\section{Study Site Description}

The experimental site is located in Shenmu County, Shaanxi Province, west China, at $38^{\circ} 50^{\prime} \mathrm{N}-39^{\circ} 47^{\prime} \mathrm{N}$, $109^{\circ} 13^{\prime} \mathrm{E}-110^{\circ} 55^{\prime} \mathrm{E}$ (Fig. 1). This area is a combination of the northern Shaanxi plateau and Mu Us sandy land. The climate is typical mid-temperate continental monsoon with cold winters and hot summers, concentrated rainfall, and with large diurnal temperature differences. The annual average temperature is around $8.4^{\circ} \mathrm{C}$, with a maximum of $38^{\circ} \mathrm{C}$ and a minimum of $-28^{\circ} \mathrm{C}$. The average annual precipitation is about $400 \mathrm{~mm}$, and the average annual evaporation is $2,211 \mathrm{~mm}$. The average altitude is about $1,300 \mathrm{~m}$. The soil type is mainly aeolian soil, and the soil is relatively barren with a pH of 7.51, available P content of $2.30 \mathrm{mg} / \mathrm{kg}$, available K of $126.4 \mathrm{mg} / \mathrm{kg}$ and a conductivity of $135.2 \mu \mathrm{s} / \mathrm{cm}$.

\section{Materials and Field Experimental Design}

The AMF strain used was Funneliformis mosseae (BGC XJ01, 1511C0001BGCAM0016) (abbreviated to F. m) supplied by Beijing Academy of Agriculture and Forestry Sciences. After propagation for 12 weeks on maize roots in pot culture, an inoculum was produced that consisted of maize root sections, mycorrhizal fungal spores and extraradical mycelium. The density of the mycelium was $4.6 \mathrm{~m} / \mathrm{g}$ soil and the spore density was 65 spores/g soil. The test plant was sea buckthorn (Hippophae rhamnoides L.) which was obtained from a local nursery. The seedlings planted were about $20 \mathrm{~cm}$ high with consistent growth branches and undeveloped roots. In April 2012, the land was leveled and the seedlings were planted in the holes dug. The plant spacing was $2 \mathrm{~m} \times 2 \mathrm{~m}$, and inoculated (F.m) and uninoculated (CK) plants were set up. After the growth of the seedlings was stable the following July, $50 \mathrm{~g}$ AM fungal inoculum was inoculated near each sea buckthorn seedling root, as the inoculation treatment, while the control plot received equivalent sterilized AMF inoculum. Conventional management and protection measures were taken after the seedlings were inoculated.

\section{Sampling Methods}

Plant growth was investigated on-site 2, 11, 14, 26 and 50 months after inoculation. The measured indexes were plant height, crown width, ground diameter and survival rate.

Two, $11,14,26$, and 50 months after inoculation, sea buckthorn rhizosphere soil samples and fine root segments of sea buckthorn were collected from both inoculated and control treatments. Each treatment was replicated five times. The root segments collected were used to determine the mycorrhizal infection rate. The rhizosphere soil samples were placed in labeled sterile plastic bags and stored at $4^{\circ} \mathrm{C}$ and then transported to the laboratory as soon as possible. Soil samples were separated into two parts, one of which was sieved to $2 \mathrm{~mm}$ and stored at $4^{\circ} \mathrm{C}$ for analysis of soil enzyme activity and microbial counts and the other was air-dried and sieved to $1 \mathrm{~mm}$ for determination of soil physical and chemical properties and extra-radical mycelium density.

\section{Quantification of Mycorrhizal Colonization Rate and Hyphal Density}

Mycorrhizal root colonization was evaluated by clearing the fine roots in $10 \% \mathrm{KOH}$ and staining with $0.05 \%(\mathrm{w} / \mathrm{v})$ Trypan blue in lacto-glycerol [22]. Root mycorrhizal colonization was assessed by the glass slide method [23]. The percentage of root mycorrhizal colonization was calculated by dividing the number of colonized roots by the total number of root samples examined.

The extral-radical mycelium was extracted using a modification of the aqueous membrane filtration technique [24]. Microfiltration membrane filters $(0.45 \mu \mathrm{m}$ pore size) containing the extracted hyphae were transferred to microscope slides and stained with two drops of $0.05 \%$ (w/v) Trypan blue in lacto-glycerol. Twenty-five visual

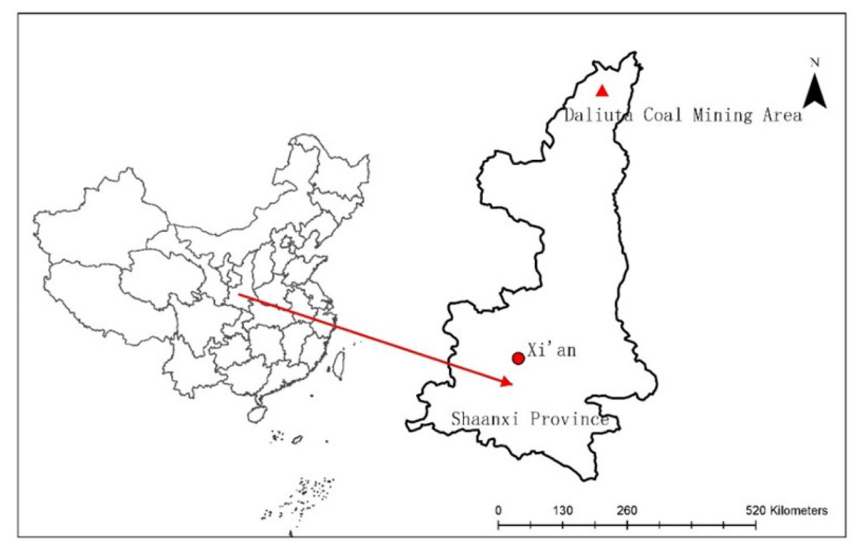

Fig. 1. Map showing the location of the study area. 
Table 1. Effects of AMF on the growth of sea buckthorn in different reclamation years.

\begin{tabular}{ccccc}
\hline Reclamation time/month & Treatment & Height/cm & Crown width/cm & Ground diameter/cm \\
\hline 2 & CK & $27.61 \pm 2.18 \mathrm{e}$ & $22.83 \pm 3.35 \mathrm{e}$ & $5.14 \pm 0.36 \mathrm{~g}$ \\
& F.m & $29.11 \pm 2.55 \mathrm{e}$ & $25.60 \pm 3.16 \mathrm{e}$ & $5.24 \pm 0.40 \mathrm{~g}$ \\
\multirow{2}{*}{11} & CK & $28.50 \pm 0.98 \mathrm{e}$ & $23.06 \pm 1.23 \mathrm{e}$ & $6.57 \pm 0.89 \mathrm{gf}$ \\
& F.m & $32.62 \pm 2.06 \mathrm{e}$ & $29.22 \pm 3.34 \mathrm{de}$ & $6.99 \pm 0.31 \mathrm{ef}$ \\
\multirow{2}{*}{14} & CK & $36.91 \pm 2.36 \mathrm{e}$ & $26.83 \pm 4.67 \mathrm{e}$ & $7.90 \pm 1.80 \mathrm{df}$ \\
& F.m & $56.76 \pm 2.51 \mathrm{~d}$ & $47.91 \pm 1.20 \mathrm{~cd}$ & $8.54 \pm 1.09 \mathrm{de}$ \\
& CK & $55.60 \pm 6.54 \mathrm{~d}$ & $59.32 \pm 3.75 \mathrm{bc}$ & $9.34 \pm 0.97 \mathrm{~cd}$ \\
& F.m & $69.06 \pm 9.46 \mathrm{c}$ & $70.63 \pm 3.56 \mathrm{~b}$ & $10.47 \pm 0.73 \mathrm{c}$ \\
& CK & $141.00 \pm 20.87 \mathrm{~b}$ & $153.20 \pm 16.54 \mathrm{a}$ & $12.73 \pm 1.07 \mathrm{~b}$ \\
& F.m & $163.80 \pm 15.04 \mathrm{a}$ & $173.0 \pm 45.92 \mathrm{a}$ & $15.70 \pm 0.95 \mathrm{a}$ \\
\hline
\end{tabular}

Data are expressed as mean \pm SD of five replicates, and different letters in each variable denote significant difference $(p<0.05)$ by least significant difference.

fields were observed at $100 \times$ magnification under a compound microscope and the mycelium density was calculated by counting the intersections using the grid cross method [25].

\section{Analysis of Soil Properties}

Soil phosphatase activity was determined using the improved method of Zhao and Jiang [26]. The sodium bicarbonate-extractable P colorimetric method was used for soil available phosphorus. Soil organic matter content was determined by external heating of potassium dichromate. Soil $\mathrm{pH}$ value and conductivity were determined by $\mathrm{pH}$ meter (soil : water ratio 2.5:1) and conductivity meter (soil : water ratio 5:1), respectively [27].

The numbers of soil microbial groups were counted using the dilution plate method [28]. The bacteria were isolated after three days of incubation at a constant temperature of $28^{\circ} \mathrm{C}$ on beef extract peptone medium containing beef extract $(0.3 \%)$, peptone $(1 \%)$ and agar $(1.8 \%)$ in deionized water, $\mathrm{pH} 7.0-7.2$; actinomycetes were cultured for four days at a constant temperature of $28^{\circ} \mathrm{C}$ on modified Gause's No. 1 synthetic medium containing soluble starch $2 \mathrm{~g}, \mathrm{KNO}_{3} 0.1 \mathrm{~g}, \mathrm{~K}_{2} \mathrm{HPO}_{4} 0.5 \mathrm{~g}, \mathrm{MgSO}_{4} \cdot 7 \mathrm{H}_{2} \mathrm{O} 0.05 \mathrm{~g}, \mathrm{NaCl} 0.05 \mathrm{~g}, \mathrm{FeSO}_{4} \cdot 7 \mathrm{H}_{2} \mathrm{O} 0.001 \mathrm{~g}$, agar $1.8 \mathrm{~g}$, deionized water $100 \mathrm{ml}, \mathrm{pH}$ 7.4-7.6; and fungi were incubated for two days at a constant temperature of $28^{\circ} \mathrm{C}$ on Martin-Bangladesh red medium containing Rose Bengal agar $3.5 \mathrm{~g}$, deionized water $100 \mathrm{ml}$, natural pH. Numbers of bacteria, actinomycetes and fungi were recorded as colony forming units (CFU)/g of dry soil.

\section{Statistical Analysis}

All data were subjected to analysis of variance (ANOVA) using the SAS software package (8.0) at the 5\% significance level. Microsoft Excel 2013 and Origin 2017 were used to process the data and figures, respectively.

\section{Results}

Plant Growth and Survival Rate

At different reclamation times the plant height, crown width and ground diameter were higher than those in the uninoculated treatment (Table 1). Compared with the uninoculated treatment, the plant height of five monitoring periods increased by $5.4 \%, 14.4 \%, 53.9 \%, 24.2 \%$, and $16.2 \%$, respectively, and the crown diameter by $12.3 \%$, $26.4 \%, 78.7 \%, 19.1 \%$, and $13.0 \%$. The ground diameter at different reclamation times increased by $4.2 \%, 6.4 \%$,

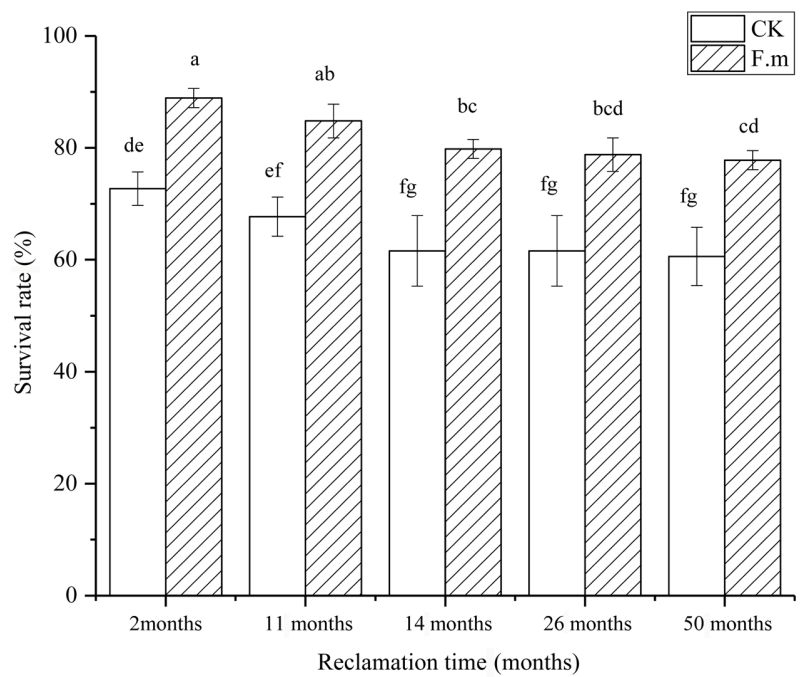

Fig. 2. Effects of AMF on the survival rate of sea buckthorn in different reclamation years. 


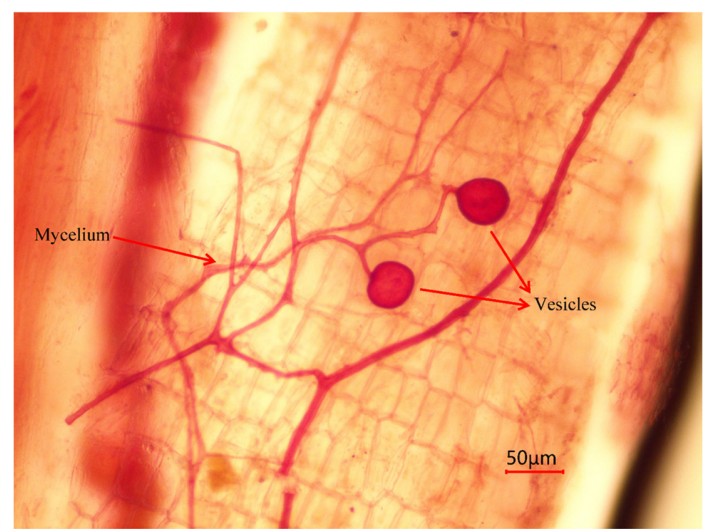

Fig. 3. Vesicles and mycelium structures of AMF in root of sea buckthorn.

$8.1 \%, 12.1 \%$, and $23.3 \%$ compared with the uninoculated treatment. The results show that inoculation with mycorrhizal fungi promoted the aboveground growth of sea buckthorn. Analysis of variance shows that AMF inoculation significantly increased plant height after 14,26, and 50 months of inoculation but crown diameter showed a significant difference only at the 14 th month. The ground diameter showed a significant difference 50 months after inoculation.

As shown in Fig. 2, two months after inoculation the survival rates of inoculated and control plants were $88.9 \%$ and $72.7 \%$, respectively. The survival rate of inoculated plants increased by $22.3 \%$. At the 11 th and 14 th months after inoculation the survival rate increased by $25.2 \%$ and $29.5 \%$, respectively. With increasing reclamation time, the survival rate of both treatments decreased, but the survival rate of the inoculated plants was higher than that of the controls, indicating that AMF inoculation effectively increased the survival rate of the plants.

\section{Mycorrhizal Characteristics}

After AMF entered the cells of the plant root cortex, the mycelium could develop into arbuscular, vesicle, root mycelium or root spore structure under appropriate conditions [10]. In Fig. 3, vesicles and mycelium could be observed, which is considered to be the evidence of mycorrhizae presence, and it could be preliminarily proved that the root system of sea buckthorn was infected by mycorrhizal fungi. As shown in Fig. 4, the mycorrhizal colonization rate of the inoculated plants was significantly (40\%) higher than that of the controls after two months, indicating that AMF formed a good symbiotic relationship with the root system. With increasing reclamation time, the mycorrhizal colonization rate of the inoculated treatment increased further and was always higher than that of the uninoculated control.

The density of mycelia can be reflected by secretion levels and overall higher activity, indicating the greater effects on mycorrhizal plants. Two months after the inoculation, the inoculated treatment and control were $3.02 \mathrm{~m} / \mathrm{g}$ and $0.94 \mathrm{~m} / \mathrm{g}$, respectively (Fig. 5). The inoculation significantly increased the length of soil mycelium, which was $221 \%$ higher than the control. At 11 and 14 months after inoculation, the inoculated treatment was

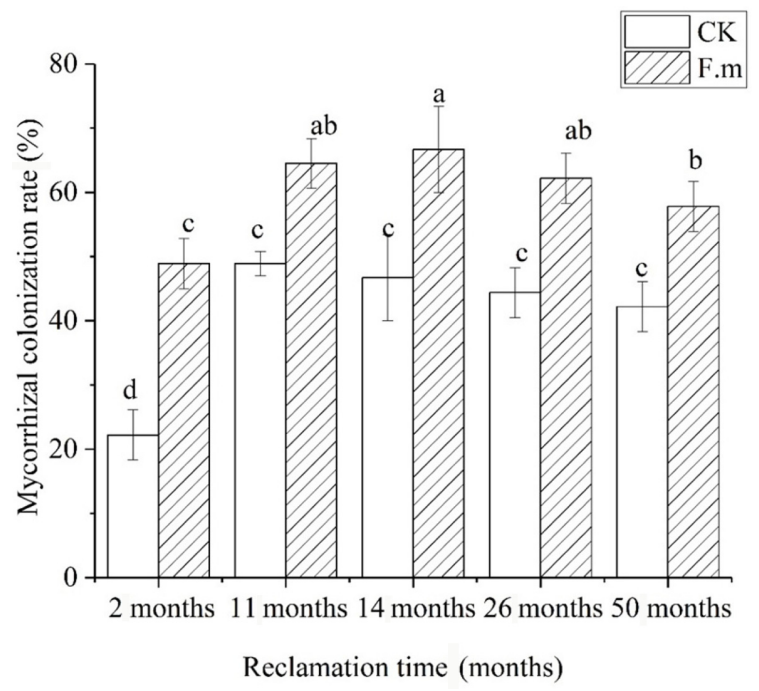

Fig. 4. Mycorrhizal colonization rate of sea buckthorn in different reclamation years. 


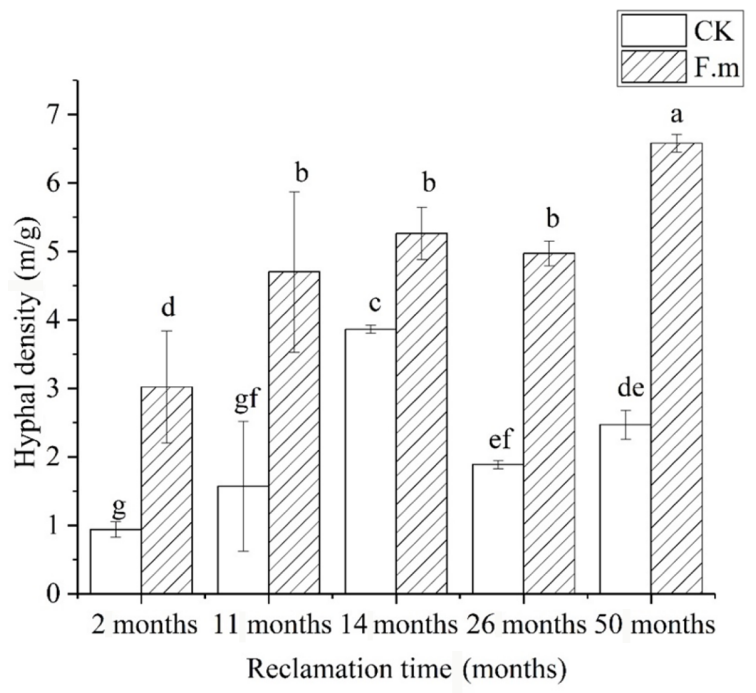

Fig. 5. Hyphal density of sea buckthorn in different reclamation years.

significantly larger than the uninoculated control treatment. The increase in mycelium can expand the absorption area of the root system and increase the amount of water and nutrients taken up by plants from the rhizosphere soil through the mycelium, thus promoting plant growth.

\section{Soil Characteristics}

The rhizosphere soil $\mathrm{pH}$ increased after the seedlings were planted and the $\mathrm{pH}$ in the mycorrhizal inoculation treatment was higher than that in the control, with significant differences between inoculated and control treatments after 2, 14 and 26 months $(p<0.05)$. After planting the soil, conductivity showed a downward trend, possibly due to the fast plant growth rate and uptake of a large number of metal cations from the soil. The soil conductivity in the mycorrhizal inoculated treatment was higher than in the control, with significant differences after 11,26 and 50 months $(p<0.05)$. This may be attributed to the mycelium absorbing and storing nutrients after the formation of mycorrhizal structures (Table 2).

Changes in available nutrients in the rhizosphere during different reclamation periods were complex. F. $\mathrm{m}$ increased the content of soil available P compared with the control two months after inoculation. From 11 to 26 months after inoculation, available $\mathrm{P}$ in the soil was lower than in the control. Fifty months after inoculation the content of available phosphorus in the rhizosphere soil was significantly higher than that in the control $(p<0.05)$. This may have been due to a deficiency of phosphorus in the rhizosphere soil due to the large amount of nutrients required for early plant growth, while with increasing reclamation time and the action of mycorrhizal fungi the activities of rhizosphere acid enzymes were enhanced and the conversion efficiency of soil phosphorus increased.

The soil organic carbon content showed a decreasing trend within 14 months of inoculation, possibly due to stimulation of the rhizosphere microbial community by AMF and increased rhizosphere bacterial activity. Increasing reclamation time led to an increase in soil organic carbon content because of large numbers of dead plant branches and leaves as well as glomalin-related soil proteins (GRSP) produced by the AM fungi [29].

\section{Soil Microorganisms and Enzyme Activities}

Soil microorganisms are important participants in the decomposition of organic matter and the cycling and metabolism of nutrients in soil, which are important soil quality evaluation indexes [30]. Two months after inoculation, the numbers of soil bacteria, fungi and actinomycetes increased significantly, reaching $139.3 \%$,

Table 2. Effects of AMF on the soil properties of sea buckthorn in different reclamation years.

\begin{tabular}{cccccc}
\hline Reclamation time/month & Treatment & $\mathrm{pH}$ & $\mathrm{Ec}(\mu \mathrm{s} / \mathrm{cm})$ & SOC $(\mathrm{g} / \mathrm{kg})$ & $\mathrm{AP}(\mathrm{mg} / \mathrm{g})$ \\
\hline 2 & CK & $7.81 \pm 0.19 \mathrm{~d}$ & $135.28 \pm 4.4 \mathrm{a}$ & $17.53 \pm 1.89 \mathrm{a}$ & $2.43 \pm 0.29 \mathrm{c}$ \\
& F. m & $8.07 \pm 0.07 \mathrm{bc}$ & $140.96 \pm 6.0 \mathrm{a}$ & $10.96 \pm 1.73 \mathrm{de}$ & $3.58 \pm 0.26 \mathrm{a}$ \\
\multirow{2}{*}{11} & CK & $8.07 \pm 0.15 \mathrm{bc}$ & $107.06 \pm 2.5 \mathrm{~cd}$ & $13.50 \pm 3.85 \mathrm{bc}$ & $2.71 \pm 0.07 \mathrm{~b}$ \\
& F. m & $8.12 \pm 0.10 \mathrm{abc}$ & $114.66 \pm 3.9 \mathrm{~b}$ & $9.33 \pm 1.84 \mathrm{ef}$ & $2.02 \pm 0.10 \mathrm{~d}$ \\
\multirow{2}{*}{14} & CK & $8.05 \pm 0.11 \mathrm{bc}$ & $61.36 \pm 4.2 \mathrm{ef}$ & $13.31 \pm 2.40 \mathrm{bcd}$ & $2.04 \pm 0.08 \mathrm{~d}$ \\
& F. m & $8.25 \pm 0.13 \mathrm{a}$ & $76.90 \pm 12.5 \mathrm{e}$ & $8.33 \pm 1.83 \mathrm{f}$ & $1.87 \pm 0.32 \mathrm{~d}$ \\
\multirow{2}{*}{26} & CK & $8.03 \pm 0.13 \mathrm{c}$ & $95.32 \pm 22.1 \mathrm{~d}$ & $8.10 \pm 0.41 \mathrm{f}$ & $2.04 \pm 0.19 \mathrm{~d}$ \\
& F. m & $8.19 \pm 0.03 \mathrm{ab}$ & $111.78 \pm 14.7 \mathrm{bc}$ & $13.67 \pm 0.19 \mathrm{bc}$ & $1.83 \pm 0.10 \mathrm{de}$ \\
\multirow{2}{*}{50} & CK & $8.02 \pm 0.08 \mathrm{c}$ & $48.22 \pm 1.5 \mathrm{f}$ & $11.91 \pm 0.19 \mathrm{~cd}$ & $1.61 \pm 0.11 \mathrm{e}$ \\
& F. m & $8.03 \pm 0.07 \mathrm{c}$ & $98.38 \pm 24.6 \mathrm{~cd}$ & $15.36 \pm 0.57 \mathrm{ab}$ & $1.90 \pm 0.25 \mathrm{~d}$ \\
\hline
\end{tabular}

Ec, electrical conductivity; SOC, soil organic carbon; AP, available phosphorus. 
Table 3. Effects of AMF on soil microorganisms and enzyme activity of sea buckthorn in different reclamation years.

\begin{tabular}{cccccc}
\hline $\begin{array}{c}\text { Reclamation time/ } \\
\text { month }\end{array}$ & Treatment & $\begin{array}{c}\text { Bacteria/ } \\
\left(10^{6} \mathrm{CFU} / \mathrm{g}\right)\end{array}$ & $\begin{array}{c}\text { Fungi/ } \\
\left(10^{4} \mathrm{CFU} / \mathrm{g}\right)\end{array}$ & $\begin{array}{c}\text { Actinomyces/ } \\
\left(10^{5} \mathrm{CFU} / \mathrm{g}\right)\end{array}$ & $\begin{array}{c}\text { Phosphatase activity/ } \\
(\mathrm{mg} / \mathrm{g})\end{array}$ \\
\hline 2 & CK & $5.09 \pm 0.80 \mathrm{ef}$ & $9.69 \pm 0.32 \mathrm{~b}$ & $4.32 \pm 0.26 \mathrm{gh}$ & $1.78 \pm 0.20 \mathrm{f}$ \\
& F. m & $12.18 \pm 1.01 \mathrm{~d}$ & $12.79 \pm 1.02 \mathrm{a}$ & $5.56 \pm 0.29 \mathrm{fg}$ & $1.71 \pm 0.11 \mathrm{f}$ \\
11 & CK & $16.07 \pm 0.86 \mathrm{c}$ & $3.94 \pm 0.45 \mathrm{de}$ & $16.07 \pm 0.86 \mathrm{~b}$ & $4.91 \pm 0.07 \mathrm{bc}$ \\
& F. m & $18.69 \pm 1.20 \mathrm{~b}$ & $7.13 \pm 1.23 \mathrm{c}$ & $18.69 \pm 1.20 \mathrm{a}$ & $5.40 \pm 0.04 \mathrm{ab}$ \\
& CK & $5.46 \pm 0.23 \mathrm{ef}$ & $0.74 \pm 0.33 \mathrm{~g}$ & $11.77 \pm 1.08 \mathrm{~d}$ & $3.16 \pm 0.07 \mathrm{e}$ \\
& F. m & $6.09 \pm 0.25 \mathrm{ef}$ & $4.47 \pm 0.26 \mathrm{de}$ & $13.33 \pm 0.26 \mathrm{c}$ & $3.58 \pm 0.16 \mathrm{de}$ \\
& CK & $4.47 \pm 2.59 \mathrm{f}$ & $1.57 \pm 0.45 \mathrm{~g}$ & $3.33 \pm 1.45 \mathrm{~h}$ & $4.36 \pm 1.73 \mathrm{~cd}$ \\
& F. m & $11.09 \pm 2.03 \mathrm{~d}$ & $3.25 \pm 0.67 \mathrm{f}$ & $6.85 \pm 0.58 \mathrm{f}$ & $6.08 \pm 0.93 \mathrm{a}$ \\
& CK & $6.62 \pm 1.53 \mathrm{e}$ & $3.78 \pm 1.69 \mathrm{ef}$ & $4.44 \pm 2.22 \mathrm{gh}$ & $5.53 \pm 0.32 \mathrm{ab}$ \\
& F. m & $28.38 \pm 1.89 \mathrm{a}$ & $5.00 \pm 0.84 \mathrm{~d}$ & $8.62 \pm 1.21 \mathrm{e}$ & $5.99 \pm 0.38 \mathrm{a}$ \\
\hline
\end{tabular}

$31.9 \%$ and $28.8 \%$, respectively, compared with the control. The increase in the soil microbial population may be due to an increase in rhizosphere secretion and the growth of plant root system. As the reclamation time increased the numbers of soil bacteria, fungi and actinomycetes in the inoculated treatment were higher than in the control. Analysis of variance shows that the number of fungi in the inoculation treatment was significantly greater than in the control at all reclamation times investigated $(p<0.05)$, and the number of actinomycetes was significantly higher except after two months of reclamation.

Soil enzyme activities are sensitive to mycorrhizal inoculation and can be used as biological indices of soil quality to evaluate the restoration process of degraded ecosystems. After inoculation with AMF, the development of the root systems accelerated and root exudation increased, promoting the physiology and metabolism of the root system. There was no effect after two months, but subsequently the soil acid phosphatase activity in the inoculation treatment was higher than in the control. The acid phosphatase activity increased by $10.0 \%, 13.2 \%$, $39.4 \%$, and $8.3 \%$, respectively, compared with the non-inoculation treatment after $11,14,26$, and 50 months. Analysis of variance shows that there were no significant differences after 2, 11, and 14 months but after 26 months the inoculation treatment was significantly higher by $39.4 \%$ over the control. This indicates that the enzyme activity increased significantly with increasing reclamation time after a functional symbiosis was formed between the mycorrhizal fungi and the root system.

\section{Discussion}

Coal mining causes large-scale surface subsidence, cracking of the soil surface, decline in soil water and fertilizer conservation capacity, and the survival and growth of local vegetation are also affected by certain adverse environmental stresses. Studies have shown that AMF can effectively increase the stress resistance of sea buckthorn and contribute to the survival of the plants under adverse conditions in sterilized soil [31, 32]. Here, inoculation significantly increased the survival rate of the plants and promoted their growth. This may be related to the large amount of mycelium produced after the formation of mycorrhizal structures which promote the uptake of water and nutrients from the soil [10]. Our results are comparable to those of Jaroszewska et al. [33]. The survival and growth of vegetation can effectively increase the vegetation cover in western mining areas, and this is important in achieving successful revegetation and control of soil loss and erosion [17, 34].

Soil disturbance has been reported to significantly reduce the density of spores and the length of extra-radical mycelium of AMF (AMF populations) compared with undisturbed soil [35]. Coal mining subsidence greatly disturbs the soil and reduces the length of extra-radical mycelium of AMF, which will have negative effects on the formation of mycorrhizas in roots [36]. There were also a large number of mycorrhizal fungi in the soil at our study area as indicated by the root colonization rate of the sea buckthorn in the control treatment and in previous studies [37]. The mycorrhizal infection rate in roots was low after cessation of coal mining and inoculation with mycorrhizal fungi increased mycorrhizal infection and mycelial density, indicating that AMF inoculation can promote AMF propagules in disturbed soils, a result consistent with Caravaca [38]. The mycorrhizal infection rate and mycelial density were still higher than those of the uninoculated control after 50 months, indicating that AMF inoculation formed a good symbiosis with the host plant over a long time period. This has very important implications for the reclamation of fragile damaged mining areas.

The microbial community plays an important role in plant growth and improvement of soil quality and is also an important indicator for soil quality evaluation. Previous studies indicate that an increase in microbial quantity and diversity in soils can reflect soil quality, and the increase in soil microbial activity has a positive effect on plant growth, root activity and rhizosphere soil metabolism [39]. Zhao et al. suggested that with an increasing number of years of reclamation the quantity of microorganisms in the soil increases greatly, and soil quality also improves significantly [40]. This may be due to the fact that the root exudates produced by plants after reclamation provide more carbohydrates for microorganisms to promote the metabolic activities of rhizosphere microorganisms. Studies show that Frankensis (a type of actinomycete) plays a key role in the nitrogen fixation ability of sea buckthorn, and Tian et al. found that inoculation with mycorrhizal fungi enhanced the nitrogen fixation ability of sea buckthorn. Inoculation with mycorrhiza may have promoted the development of the actinomycete Frankia and improved nitrogen fixation ability [32]. Huang et al. showed that inoculation with mycorrhizal fungi significantly increased the number of fungi in soil in which white clover was growing but had little effect on the 
number of bacteria in the soil, while Li et al. found that AMF increased the numbers of bacteria and actinomycetes and reduced the number of fungi $[41,42]$. Here, AMF improved the rhizosphere microenvironment, nutrient status and organic matter content, together with the acid phosphatase activity, which may have contributed to the increase in the number of microorganisms and in the metabolic activity of the rhizosphere. Unfortunately, the rhizosphere soil microbial community structure in AMF-inoculated and control treatments were not examined. Previous studies showed that AMF had a significant effect on the rhizosphere bacterial community and could significantly increase the bacterial diversity index in sea buckthorn root system, which indicated that AMF inoculation may affect microbial community composition [43-45]. Changes in soil microbial community structure merit further study.

At present, there are many successful examples of mycorrhizal application in field reclamation [46-48]. However, not all reports are positive. For example, a field study conducted by Stahl et al. showed that AMF inoculation produced no significant difference, which the authors attributed mainly to the ecological adaptability of mycorrhiza [49]. Kohler et al. reported that a combination of compost addition and arbuscular mycorrhizal inoculation rather than the separate use of each of these exerted effects on the growth of shrub species [50]. In addition, some studies show that indigenous AMF give the maximum effect [51]. Therefore, in order to ensure the success of reclamation, a series of factors need to be considered in the process of mycorrhizal microbial reclamation, such as the production and quality control of microbial agents in large-scale microbial reclamation, species compatibility with the target environment (e.g., edaphic and climatic conditions in the reclamation area), the degree of spatial competition with other soil organisms in the target niche, host plant species and cultivars, and the timing of inoculation $[52,53]$. Furthermore, small-scale field experiments are needed before large-scale mycorrhizal reclamation is attempted.

\section{Acknowledgments}

We thank Dr. Peter Christie for revising the manuscript. The study was funded by the National Natural Science Foundation of China (51974326) and the Capital Science and Technology Talents Training Project (Beijing) (Z18110006318021).

\section{Conflict of Interest}

The authors have no financial conflicts of interest to declare.

\section{References}

1. Bian ZF, Inyang HI, Daniels JL, Otto F, Struthers S. 2010. Environmental issues from coal mining and their solutions. Min. Sci. Technol. (Xuzhou, China). 20: 215-223.

2. Chugh YP. 2018. Concurrent mining and reclamation for underground coal mining subsidence impacts in China. Int. J. Coal Sci. Technol. 5: 18-35.

3. Hu H, Lian X. 2015. Subsidence rules of underground coal mines for different soil layer thickness: Lu'an Coal Base as an example, China. Int. J. Coal Sci. Technol. 2: 178-185.

4. Huang Y, Tian F, Wang YJ, Wang M, Hu ZL. 2015. Effect of coal mining on vegetation disturbance and associated carbon loss. Environ. Earth Sci. 73: 2329-2342.

5. Yang DJ, Bian ZF, Lei SG. 2016. Impact on soil physical qualities by the subsidence of coal mining: a case study in Western China. Environ. Earth Sci. 75: 652

6. Shi PL, Zhang YX, Hu ZQ, Ma K, Wang H, Chai TY. 2017. The response of soil bacterial communities to mining subsidence in the west China aeolian sand area. Appl. Soil Ecol. 121: 1-10.

7. Lei SG, Bian ZF, Daniels JL, He X. 2010. Spatio-temporal variation of vegetation in an arid and vulnerable coal mining region. Min. Sci. Technol. (Xuzhou, China) 20: 485-490.

8. Asmelash F, Bekele T, Birhane E. 2016. The potential role of arbuscular mycorrhizal fungi in the restoration of degraded lands. Front. Microbiol. 7: 1095.

9. Zhao RX, Guo W, Bi N, Guo JY, Wang LX, Zhao J, et al. 2015. Arbuscular mycorrhizal fungi affect the growth, nutrient uptake and water status of maize (Zea mays L.) grown in two types of coal mine spoils under drought stress. Appl. Soil Ecol. 88: 41-49.

10. Choi J, Summers W, Paszkowski U. 2018. Mechanisms underlying establishment of arbuscular mycorrhizal symbioses. Annu. Rev. Phytopath. 56: 135-160.

11. Paradis R, Dalpé Y, Charest, C. 1995. The combined effect of arbuscular mycorrhizas and short-term cold exposure on wheat. New Phytol. 129: 637-642.

12. Rodríguez-Caballero G, Caravaca F, Fernández-González AJ, Alguacila MM, Fernández-López M, Roldána A. 2017. Arbuscular mycorrhizal fungi inoculation mediated changes in rhizosphere bacterial community structure while promoting revegetation in a semiarid ecosystem. Sci. Total Environ. 584: $838-848$

13. Pollastri S, Savvides A, Pesando M, Lumini E, Volpe MG, Ozudogru EA, et al. 2018. Impact of two arbuscular mycorrhizal fungi on Arundo donax L. response to salt stress. Planta 247: 573-585.

14. Miransari M. 2010. Contribution of arbuscular mycorrhizal symbiosis to plant growth under different types of soil stress. Plant Biol. 12: 563-569.

15. Bona E, Cantamessa S, Massa N, Manassero P, Marsano F, Copetta A, et al. 2017. Arbuscular mycorrhizal fungi and plant growthpromoting pseudomonads improve yield quality and nutritional value of tomato: a field study. Mycorrhiza 27: 1-11.

16. Jeffries P, Gianinazzi S, Perotto S, Turnau K, Barea JM. 2003. The contribution of arbuscular mycorrhizal fungi in sustainable maintenance of plant health and soil fertility. Biol. Fert. Soils 37: 1-16.

17. Mardhiah U, Caruso T, Gurnell A, Rillig MC. 2016. Arbuscular my corrhizal fungal hyphae reduce soil erosion by surface water flow in a greenhouse experiment. Appl. Soil Ecol. 99: 137-140.

18. Manaut N, Sanguin H, Ouahmane L, Bressan M, Thioulouse J, Baudoin E, et al. 2015. Potentialities of ecological engineering strategy based on native arbuscular mycorrhizal community for improving afforestation programs with carob trees in degraded environments. Ecol. Eng. 79: 113-119.

19. Karthikeyan A, Krishnakumar N. 2012. Reforestation of bauxite mine spoils with Eucalyptus tereticornis Sm. seedlings inoculated with arbuscular mycorrhizal fungi. Ann. For. Res. 55: 207-216. 
20. Li SP, Bi YL, Kong WP, Wang J, Yu HY. 2015. Effects of the arbuscular mycorrhizal fungi on environmental phytoremediation in coal mine areas. Russ. J. Ecol. 46: 431-437.

21. Bi YL, Zhang J, Song ZH, Wang ZG, Qiu L, Hu JJ, et al. 2019.Arbuscular mycorrhizal fungi alleviate root damage stress induced by simulated coal mining subsidence ground fissures. Sci. Total Environ. 652: 398-405.

22. Phillips JM, Hayman DS. 1970. Improved procedures for clearing roots and staining parasitic and vesicular-arbuscular mycorrhizal fungi for rapid assessment of infection. Trans. Br. Mycol. Soc. 55: 158-161

23. Giovannetti M, Mosse B. 1980. An evaluation of technique for measuring vesicular-arbuscular mycorrhizae infection in roots. New Phytol. 84: 489-500.

24. Jakobsen I, Abbott LK, Robson AD. 1992. External hyphae of vesicular-arbuscular mycorrhizal fungi associated with Trifolium subterraneum L. 1. Spread of hyphae and phosphorus inflow into roots. New Phytol. 120: 371-380.

25. Gryndler M, Larsen J, Hršelová H, Řezáčová V, Gryndlerová H, Kubát J. 2006. Organic and mineral fertilization, respectively, increase and decrease the development of external mycelium of arbuscular mycorrhizal fungi in a long-term field experiment. Mycorrhiza 16: 159-166.

26. Zhao LP, Jiang Y.1986. Determination of the method of soil phosphatase activity. Chin. J. Soil Sci. 17: 138-142.

27. Bao SD. 2000. Soil agricultural chemistry analysis, pp. 117-128. 2nd Ed. Agriculture Press, Beijing.

28. Shen P, Fan XR, Li GB. 1999. Microbiology experiment, pp. 123-128. Higher Education Press, Beijing.

29. Verbruggen E, Jansa J, Hammer E C, Rillig MC. 2016. Do arbuscular mycorrhizal fungi stabilize litter-derived carbon in soil?. J. Ecol. 104: $261-269$

30. Ye SP, Yang YJ, Xin GR, Wang YT, Ruan L, Ye GR. 2015. Studies of the Italian ryegrass-rice rotation system in southern China: Arbuscular mycorrhizal symbiosis affects soil microorganisms and enzyme activities in the Lolium mutiflorum L. rhizosphere. Appl. Soil Ecol. 90: 26-34.

31. Tang M, Xue S, Ren JH, Hu JJ, Liu JC. 2003. Mechanism of the promotion of drought resistance of Hippophae rhamnoides with arbuscular mycorrhizal fungi. J. Northeast. For. Univ. 18: 29-31.

32. Tian CJ, He XY, Zhong Y, Chen JK. 2002. Effects of VA mycorrhizae and Frankia dual inoculation on growth and nitrogen fixation of Hippophae tibetana. For. Ecol. Manage. 170: 307-312.

33. Jaroszewska A, Biel W, Telesinski A. 2018. Effect of mycorrhization and variety on the chemical composition and antioxidant activity of sea buckthorn berries. J. Elem. 23: 673-684.

34. Estaún V, Savé R, Biel C. 1997. AM inoculation as a biological tool to improve plant revegetation of a disturbed soil with Rosmarinus officinalis under semi-arid conditions. Appl. Soil Ecol. 6:223-229.

35. Trejo D, Barois I, Sangabriel-Conde W. 2015. Disturbance and land use effect on functional diversity of the arbuscular mycorrhizal fungi. Agrofor. Syst. 90: 265-279.

36. Jasper DA, Abbott LK, Robson AD.1989. Soil disturbance reduces the infectivity of external hyphae of vesicular-arbuscular mycorrhizal fungi. New Phytol. 112: 93-99.

37. He XL, Chen C, He B. 2011. Spatial distribution of arbuscular mycorrhizal fungi and glomalin of Hippophae rhamnoides L. in farming-pastoral zone from the two northern provinces of China. Acta Ecologica Sinica 31: 1653-1661.

38. Caravaca F, Alguacil M M, Barea J M, Roldána A. 2005. Survival of inocula and native AM fungi species associated with shrubs in a degraded Mediterranean ecosystem. Soil Biol. Biochem. 37: 227-233.

39. Ozores-Hampton M, Stansly P A, Salame T P. 2011. Soil chemical, physical, and biological properties of a sandy soil subjected to long-term organic amendments. J. Sustain. Agr. 35: 243-259.

40. Zhao Z, Shahrour I, Bai Z, Fan W, Feng L, Li H. 2013. Soils development in opencast coal mine spoils reclaimed for 1-13 years in the West-Northern Loess Plateau of China. Eur. J. Soil Biol. 55: 40-46.

41. Huang YZ, Zhong M, Wu W, Sui LH, Zhang C, Hao XW. 2014. Effects of Arbuscular mycorrhizal fungi isolated from white clovers (Trifolium repens L.) on soil bacteria and fungi. Chem. Ecol. 30: 118-132.

42. Li Y, Chen Y, Li M, Lin X, Liu R. 2012. Effects of arbuscular mycorrhizal fungi communities on soil quality and the growth of cucumber seedlings in a greenhouse soil of continuously planting cucumber. Pedosphere. 22: 79-87.

43. Bi Y, Wang K, Wang J. 2018. Effect of different inoculation treatments on AM fungal communities and the sustainability of soil remediation in Daliuta coal mining subsidence area in northwest China. Appl. Soil Ecol. 132: 107-113.

44. Zhang HQ, Tang M, Chen H, Tian ZQ, Xue YQ, Feng Y. 2010. Communities of arbuscular mycorrhizal fungi and bacteria in the rhizosphere of Caragana korshinkii and Hippophae rhamnoides in Zhifanggou watershed. Plant Soil. 326: 415-424.

45. Feng Y, Tang M, Chen H, Zhang H, Cong W, Zhang H. 2011. Community diversity of bacteria and arbuscular mycorrhizal fungi in the rhizosphere of Amorpha fruticosa L., Hippophae rhamnoides L. and Robinia pseudoacacia L. in different ecological regions of Loess Plateau in Shaanxi Province of China. Afr. J. Microbiol. Res. 5: 4787-4795.

46. Torrez V, Ceulemans T, Mergeay J, de Meester L, Honnay O. 2016. Effects of adding an arbuscular mycorrhizal fungi inoculum and of distance to donor sites on plant species recolonization following topsoil removal. Appl. Veg. Sci. 19: 7-19.

47. Giri B, Kapoor R, Mukerji KG. 2005. Effect of the arbuscular mycorrhizae Glomus fasciculatum and G. macrocarpum on the growth and nutrient content of Cassia siamea in a semi-arid Indian wasteland soil. New For. 29: 63-73.

48. Wulandari D, Cheng W, Tawaraya K. 2016. Arbuscular mycorrhizal fungal inoculation improves Albizia saman and Paraserianthes falcataria growth in post-opencast coal mine field in East Kalimantan, Indonesia. For. Ecol. Manage. 376: 67-73.

49. Davidson BE, Novak SJ, Serpe MD. 2016. Consequences of inoculation with native arbuscular mycorrhizal fungi for root colonization and survival of Artemisia tridentata ssp. wyomingensis seedlings after transplanting. Mycorrhiza 26: 595-608.

50. Kohler J, Caravaca F, Azcón R, Díaze G, Roldánc A. 2015. The combination of compost addition and arbuscular mycorrhizal inoculation produced positive and synergistic effects on the phytomanagement of a semiarid mine tailing. Sci. Total Environ. 514: 42-48.

51. Ortiz N, Armada E, Duque E, Roldán A, Azcón R. 2015. Contribution of arbuscular mycorrhizal fungi and/or bacteria to enhancing plant drought tolerance under natural soil conditions: effectiveness of autochthonous or allochthonous strains. J. Plant Physiol. 174: 87-96.

52. Berruti A, Lumini E, Balestrini R, Bianciotto V. 2016. Arbuscular mycorrhizal fungi as natural biofertilizers: let's benefit from past successes. Front. Microbiol. 6: 1559.

53. Back MM, Altmann T, Souza PVD. 2016. Influence of arbuscular mycorrhizal fungi on the vegetative development of citrus rootstocks1. Pesqui. Agropecu. Trop. 46: 407-412. 